\title{
A comparison of mechanical properties and X-ray tomography analysis of different out-of-autoclave manufactured thermoplastic composites
}

\author{
Diego Saenz-Castillo ${ }^{1,2}$, María I Martín ${ }^{1,2}$, \\ Vanessa García-Martínez', Abhiram Ramesh ${ }^{3}$, Mark Battley ${ }^{4}$ \\ and Alfredo Güemes ${ }^{2}$ (1)
}

\begin{abstract}
Three different out-of-autoclave manufacturing processes of CF/poly-ether-ether-ketone thermoplastic composites were characterized, including innovative laser-assisted automated fibre placement with in situ consolidation. Characterization techniques included differential scanning calorimetry, ultrasonic non-destructive testing and matrix digestion, in addition to 3D X-ray microcomputed tomography to investigate the void distribution, size and shape. The results revealed that in situ consolidation process can lead to the accumulation of large voids between the upper layers. Interlaminar shear, in-plane shear, tensile and flexure testing were used for mechanical evaluation. A reduction in the mechanical properties was observed for in situ consolidation laminates when compared to the other out-of-autoclave methods. The drop in mechanical properties of in situ consolidation laminates was mainly attributed to the differences found in void distribution and size. Optimization of processing parameters along with higher quality prepreg raw material could be of assistance for the improvement of mechanical properties of in situ consolidation structures.
\end{abstract}

\section{Keywords}

Thermoplastic composites, microcomputed tomography analysis, mechanical testing, out-of-autoclave, in situ consolidation

\section{Introduction}

Depending on many key factors such as process efficiency, cost and geometrical features, a specific manufacturing process may be selected for the fabrication of a composite element. Thus, the automatic lamination of composite materials is a widely used technique for the lay-up of composite structures in the aerospace and automotive industries. Technologies such as automatic tape lay-up and automated fibre placement (AFP) have reached the highest degree of technological readiness level regarding the processing of thermoset-matrix composites. Therefore, many primary aerostructures are laminated by these techniques and later cured in autoclave. However, the automatic lamination of thermoplastic composites is still under research, and consequently achieving the same production level as thermoset processing is challenging. Even though it was a technology studied during the decade of the $1980 \mathrm{~s},{ }^{14}$ there is a renewed interest in thermoplastic lamination ${ }^{52}$ that could be mainly attributed to technological advances, such as the recent development of promising heat

\footnotetext{
'FIDAMC, Foundation for the Research, Development and Application of Composite Materials, Spain

${ }^{2}$ Departamento de Materiales y Producción Aeroespacial, E.T.S.I. Aeronáutica y del Espacio, Universidad Politécnica de Madrid, Spain ${ }^{3}$ Centre for Advanced Composite Materials, Department of Mechanical Engineering, University of Auckland, New Zealand

${ }^{4}$ Centre for Advanced Composite Materials, Department of Engineering Science, University of Auckland, New Zealand
}

\section{Corresponding author:}

Diego Saenz-Castillo, FIDAMC, Foundation for the Research, Development and Application of Composite Materials, Avenida Rita Levi Montalcini 29, Tecnogetafe, Getafe 28906, Madrid, Spain.

Email: diego.saenz@fidamc.es 
sources which may offer low power consumption as diode laser, modern industrial automated equipment like multi-tow heads, and higher quality thermoplastic prepregs.

The lamination of thermoplastic composites has a huge potential, mainly due to the fact that no extra autoclave or oven consolidation is required with the so-called in situ consolidation (ISC) process. Other notable advantages of the process are a smaller partsize limitation and net-shape manufacturing. ${ }^{21}$ In a typical thermoplastic automated fibre placement (TP-AFP) process, an incoming thermoplastic prepreg tape is pulled from a spool and guided by a system of pulleys. A heat source (e.g. a laser or a gas torch) is used to heat up the incoming tape and substrate material above the polymer melting point. The tape is then consolidated by a compaction roller over a substrate consisting of previously consolidated layers.

Due to the elevated structural requirements of aeronautics, high-performance thermoplastic polymers are commonly studied. Poly-aryl ether-ketone polymers family is the most attractive for the aerospace industry and many studies regarding poly-ether-ketone-ketone and poly-ether-ether-ketone (PEEK) can be found in the literature, ${ }^{8,13,22}$ as well as research related to other high-performance thermoplastic polymers such as polyamide, poly-phenylene-sulphide or polyetherimide. The main advantages of thermoplastic polymers when compared to thermoset have been widely reported in the literature ${ }^{2325}$ as excellent mechanical properties and behaviour against impact, no need of cold storage owing to long shelf-life times, no chemical reaction during the consolidation and the opportunity for new out-of-autoclave (OoA) manufacturing processes, such as ISC. Many other manufacturing processes are nowadays under research, such as over-moulding, ${ }^{26}$ thermoforming or thermoplastic welding. ${ }^{27}$ Despite their many advantages, thermoplastic composites also have drawbacks including typically high-viscosity which makes the processability more complex. Also, higher processing temperatures in the range of $350-400^{\circ} \mathrm{C}$ are typically required during manufacturing, apart from the use of specific ancillary materials.

Automatic lamination of thermoplastic composites is a high-complexity process where many physical phenomena take place, such as thermal transfer, crystallization and intimate contact, among others, ${ }^{5,10,21,28}$ In contrast with more conventional manufacturing methods, the key phenomena occur during a very short time (typically few milliseconds). At the time when the resin is melted, the polymer chains are diffused and the voids occluded into the raw tapes must be evacuated during the consolidation of the roller, followed by ultra-fast cooling down, in the order of $10,000-15,000^{\circ} \mathrm{C} / \mathrm{min}$. The main manufacturing parameters consist of applied temperature profiles (related to laser power), compaction force, deposition speed and tool temperature, ${ }^{6,16,17,29,30}$ which have a large impact on the final performance of the thermoplastic structures. The effect of the cooling rate in thermoplastic composites is crucial since it is directly related to the matrix crystallization and therefore to the mechanical response, ${ }^{8,31}$ Typical cooling rates of above $10,000^{\circ} \mathrm{C} / \mathrm{min}$ in ISC processing are significantly faster than the typical $1-5^{\circ} \mathrm{C} / \mathrm{min}$ in autoclave, oven or hot-press cycles. Due to the nature of the manufacturing process itself, a higher void content level (porosity) can occur in the ISC process compared to other fabrication methods such as vacuum bag-only (VBO) in oven. ${ }^{17}$ Not only a higher void volume fraction can be expected, but also different void distribution and shape may be observed in in situ consolidated structures, which may also affect the final mechanical performance.

Due to the complexity of the ISC process and the high number of physical phenomena and processing parameters involved, it becomes difficult to control and optimize the process, and it is common to face some reduction in mechanical properties when thermoplastic structures processed by ISC are compared to autoclave levels. This has also been previously reported in the literature. For instance, Comer et al ${ }^{8}$ reported the lowering of different mechanical properties compared to autoclave when processing carbon fibre (CF)/PEEK with a laser-assisted ISC machine working at relatively high lamination speeds $(8-12 \mathrm{~m} / \mathrm{min})$, $420^{\circ} \mathrm{C}$ at the nip point and a silicone roller applying a 1.2-bar pressure. They presented the mechanical properties relative to autoclaved specimens. Compared to autoclave specimens, their ISC processed specimens had relative strengths of $68 \%$ in flexural strength, $70 \%$ in interlaminar shear strength (ILSS) and $78 \%$ in open-hole compression strength. Nevertheless, they also reported a higher interlaminar toughness $(134 \%)$. The overall decrease in properties was mainly attributed to incomplete melt of resin, low crystallinity and voids rebound during the lamination. Schledjewski and Miaris ${ }^{32}$ reported $94 \%$ of autoclaved mechanical properties with slower lamination speed of $6 \mathrm{~m} / \mathrm{min}$. Rodriguez-Lence et al. ${ }^{9}$ reported the strength of different properties of laser-assisted AFP samples to be in the range of $75-85 \%$ of oven consolidated reference laminates. Those studies indicated the need of higher quality raw prepreg tapes for decreasing the final void content, therefore increasing the mechanical properties closer to autoclaved levels. ${ }^{33,34}$ Higher quality thermoplastic tapes may consist of low intralaminar void content, good fibre and matrix distribution and parallel surfaces. In the meanwhile, low deposition speed, high compaction forces, good lay-up strategies, self-heated tools and a proper temperature control are 
generally proposed to address good quality thermoplastic parts. ${ }^{7,21,28}$ Even though those studies reported the drop of mechanical properties in ISC laminates pointing multiple reasons, we identified a gap in this research field, since a deep study regarding the void morphology and distribution of ISC laminates is not available in the literature.

For the quality control of the manufactured composite parts in the aerospace industry, ultrasonic nondestructive testing (NDT) and void content assessment are commonly used, complemented with some mechanical testing such as ILSS for curing cycle validation. Conventional void volume fraction characterization techniques as matrix digestion ${ }^{35,36}$ allow measurement of averaged void volume fraction but do not enable a deeper characterization of void distribution and shape. Optical 2D microscopy is a very useful technique for a fast study of production defects but has considerable limitations and drawbacks being a destructive method since the part must be cut out and surface polished. ${ }^{37}$ On the other hand, innovative techniques as X-ray 3D microcomputed tomography (micro-CT) has been proved to be a promising technique in composites defect characterization. ${ }^{38} 40$ Micro-CT can not only provide an averaged void volume fraction value, but it can also be used to study more relevant aspects such as void size, shape and distribution in the whole specimen, without being limited to a single crosssection of the coupon. For the understanding of the porosity impact on the mechanical properties, the research should not be limited to an averaged void volume fraction, but should also be focused on individual void features and distribution, which have been shown to be sometimes more important for the mechanical failure than the averaged void fraction itself. $^{39}$

A previous investigation of the authors evaluated the impact of processing parameters of several thermoplastic manufacturing methods and related them to mechanical properties and averaged void volume fraction. ${ }^{17}$ Critical void volume fractions where in-plane shear (IPS) properties started to decrease were identified. Also, a correlation with the ultrasonic attenuation was performed.

In this work, a set of APC2-AS4 laminates were manufactured by three OOA methods including VBO, hot-press and ISC in order to perform a deep comparison of mechanical response and porosity among the manufacturing methods. The research includes X-ray computed tomography analysis, differential scanning calorimetry (DSC) and more mechanical testing compared to our previous work. Micro-CT imaging was undertaken to characterize void shape, distribution and size. The set of the analysed mechanical properties was expanded to account for not only key matrix- dominated properties, but also fibre-dominated properties. The main purpose of this work was focused on investigating the mechanical response of ISC laminates and the relation to void size and distribution inherent to the ISC process when working with APC2-AS4. The VBO laminates were set as the baseline due to their excellent performance. To the best of our knowledge, the present study is the first to present and compare a deep void distribution analysis performed by micro-CT of ISC laminates and compared to other manufacturing techniques.

\section{Materials and experimental procedure}

\section{Material and configuration}

Unidirectional $C F / P E E K$ thermoplastic prepreg material (APC2-AS4) supplied by Cytec Solvay Group ${ }^{41}$ was selected for this work. The material consisted of PEEK base polymer reinforced with standard modulus carbon fibre. Prepreg fibre areal weight was $145 \mathrm{~g} / \mathrm{m}^{2}$ and the resin weight content was $34 \%$. Conventional $300-\mathrm{mm}$ wide tape format was used for hand-lay-up and subsequent oven or hot-press consolidation. For ISC lamination, the same material but slit to $6.35-\mathrm{mm}$ wide tapes was used during the ISC process. APC2-AS4 was selected for this study since it is a widely studied material for OoA processing. Thus, it was considered to be of great interest to research its application into automatic lamination.

Two different stacking sequences were used in this study, $[0]_{16}$ and $[45,-45]_{45}$ with panel dimensions of $300 \times 300 \times 2.16 \mathrm{~mm}$. One laminate of each lay-up sequence was manufactured by each of the three technologies in this study resulting on a total of six laminates being manufactured. The details of the laminates manufacturing are given in the next sub-sections and compiled in Table 1.

\section{Laminate manufacturing}

VBO in oven monufocturing. Thermoplastic laminates manufactured by VBO in this study were processed following aerospace standard procedures, according to manufacturer data sheet. ${ }^{42,43}$ Two 16-ply laminates corresponding to stacking $[0]_{16}$ and $[45 /-45]_{4 S}$ were consolidated in an oven. A flat steel tool with an incorporated grid as air evacuation path was used. The thermoplastic preform was located between two polyimide sheets (kapton) with demoulding agents. A high temperature breather was located on the top of it, and the vacuum bag was sealed against the tooling by using high temperature sealant tape. Manufacturing parameters applied during consolidation are listed in Table 1 and were set according to the supplier data sheet. ${ }^{42}$ 
Table I. Key manufacturing parameters used during the laminates manufacturing.

\begin{tabular}{|c|c|c|c|c|c|c|}
\hline \multirow[b]{2}{*}{$\begin{array}{l}\text { Manufacturing } \\
\text { technology }\end{array}$} & \multirow[b]{2}{*}{$\begin{array}{l}\text { Laminate } \\
\text { code }\end{array}$} & \multirow[b]{2}{*}{$\begin{array}{l}\text { Stacking } \\
\text { sequence }\end{array}$} & \multicolumn{3}{|c|}{ Manufacturing process parameters } & \\
\hline & & & $\begin{array}{l}\text { Consolidation } \\
\text { temperature }\left({ }^{\circ} \mathrm{C}\right)\end{array}$ & Dwell time $(\mathrm{min})$ & Vacuum level (mbar) & \\
\hline \multirow{3}{*}{$\begin{array}{l}\text { Vacuum bag-only } \\
\text { (VBO) }\end{array}$} & VBO_0 & {$[0]_{16}$} & 400 & 15 & 100 & \\
\hline & VBO_45 & {$[45 /-45]_{4 S}$} & & & & \\
\hline & & & $\begin{array}{l}\text { Consolidation } \\
\text { temperature }\left({ }^{\circ} \mathrm{C}\right)\end{array}$ & Dwell time (min) & $\begin{array}{l}\text { Pressure on } \\
\text { laminate }(\mathrm{MPa})\end{array}$ & \\
\hline \multirow[t]{3}{*}{ Hot-press } & HP_O & {$[0]_{16}$} & 400 & 15 & 0.7 & \\
\hline & HP_45 & {$[45 /-45]_{4 S}$} & & & & \\
\hline & & & $\begin{array}{r}\text { Average laser } \\
\text { power }(\mathrm{W})\end{array}$ & $\begin{array}{l}\text { Tooling } \\
\text { temperature }\left({ }^{\circ} \mathrm{C}\right)\end{array}$ & $\begin{array}{l}\text { Consolidation } \\
\text { force }(\mathrm{N})\end{array}$ & $\begin{array}{l}\text { Lamination } \\
\text { speed }(\mathrm{m} / \mathrm{min})\end{array}$ \\
\hline \multirow{2}{*}{$\begin{array}{l}\text { In situ consolidation } \\
\text { (ISC) }\end{array}$} & ISC_O & {$[0]_{16}$} & 180 & 200 & 500 & 2 \\
\hline & ISC_45 & {$[+45 /-45]_{4 S}$} & & & & \\
\hline
\end{tabular}
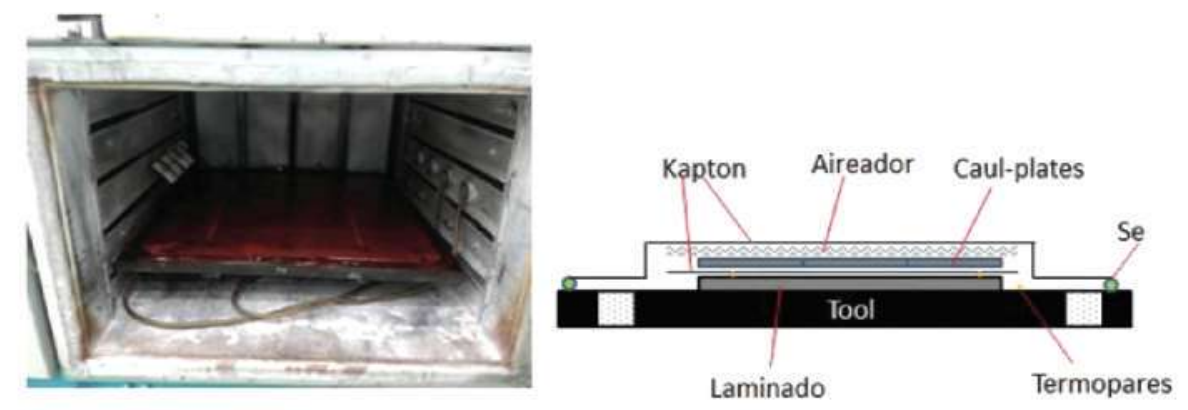

Figure I. VBO manufacturing: high temperature vacuum bag inside the oven ready for consolidation cycle (left) and VBO manufacturing set-up scheme (right).

During the consolidation cycle, the temperature was maintained for a dwell time of $15 \mathrm{~min}$ once the consolidation temperature of $400 \pm 10^{\circ} \mathrm{C}$ was reached. Temperature and vacuum values were monitored during the cycle with embedded thermocouples and vacuum sensor. Heat and cooling ramps were performed at $2^{\circ} \mathrm{C} / \mathrm{min}$, in order to obtain an adequate degree of crystallinity. An illustration of VBO set-up is shown in Figure 1.

Hot-press manufacturing. A scheme of hot-press manufacturing is illustrated in Figure 2. The manufacturing configuration was based in the supplier data sheets. ${ }^{42,43}$ The prepreg material was hand-lay-up applying several welding points with a manual welder. The laminate was located inside a metallic frame (thinner than the nominal thickness of thermoplastic laminate) which worked as material retainer. Two kapton sheets with release agent were located on the bottom and the top of the laminate. Two metallic caul plates were used for obtaining flat surfaces. The key manufacturing parameters were set according to the supplier data sheet and are compiled in Table 1. The temperature was increased up to $400^{\circ} \mathrm{C}$ and maintained for $15 \mathrm{~min}$ before cooling down. Contact pressure was applied until the cycle reached consolidation temperature, after which the pressure was increased and maintained to $0.7 \mathrm{MPa}$ for the rest of the cycle. The temperature was monitored by an embedded thermocouple and the hot-press control device. Heating and cooling ramps were performed at $2^{\circ} \mathrm{C} / \mathrm{min}$.

Laser-assisted AFP with ISC manufacturing. ISC was performed with a gantry-style single-tow deposition machine developed by MTorres. A diode laser was used as heating source which created a profile with a heating area of $140 \mathrm{~mm}$ in the lamination direction and $7.5 \mathrm{~mm}$ in transverse direction. A spool system orientated an incoming tow which was also heated by the laser. A self-heated tooling was used for minimizing the effect of residual stress and also preventing the tool from acting as a heat sink. Manufacturing parameters 

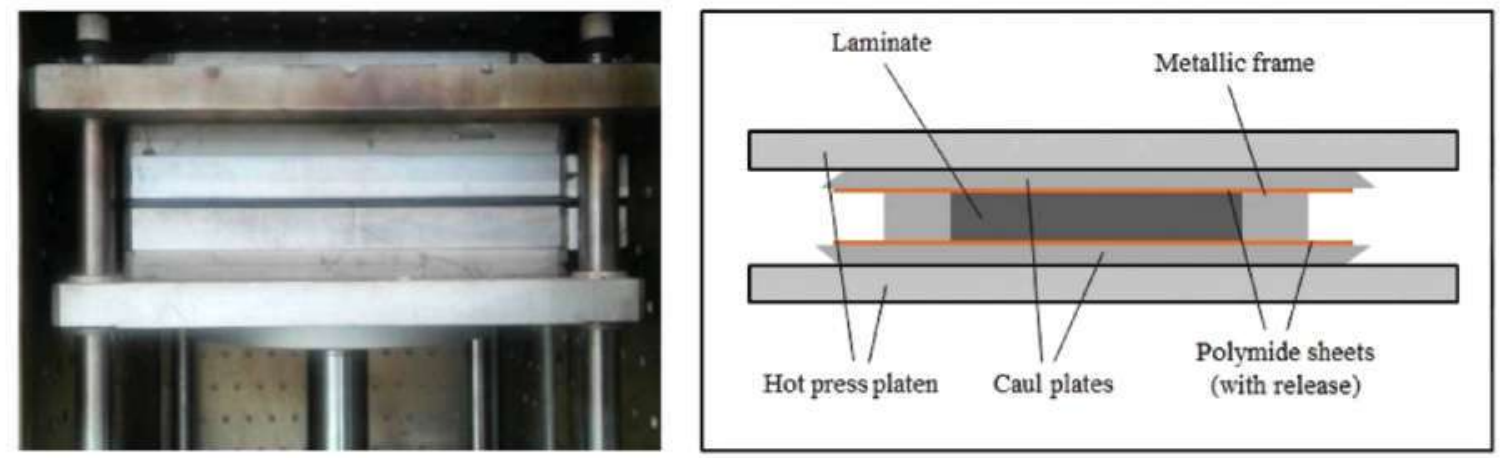

Figure 2. Hot-press manufacturing: laminate located in the hot-press ready for consolidation cycle (left) and hot-press set-up scheme (right).
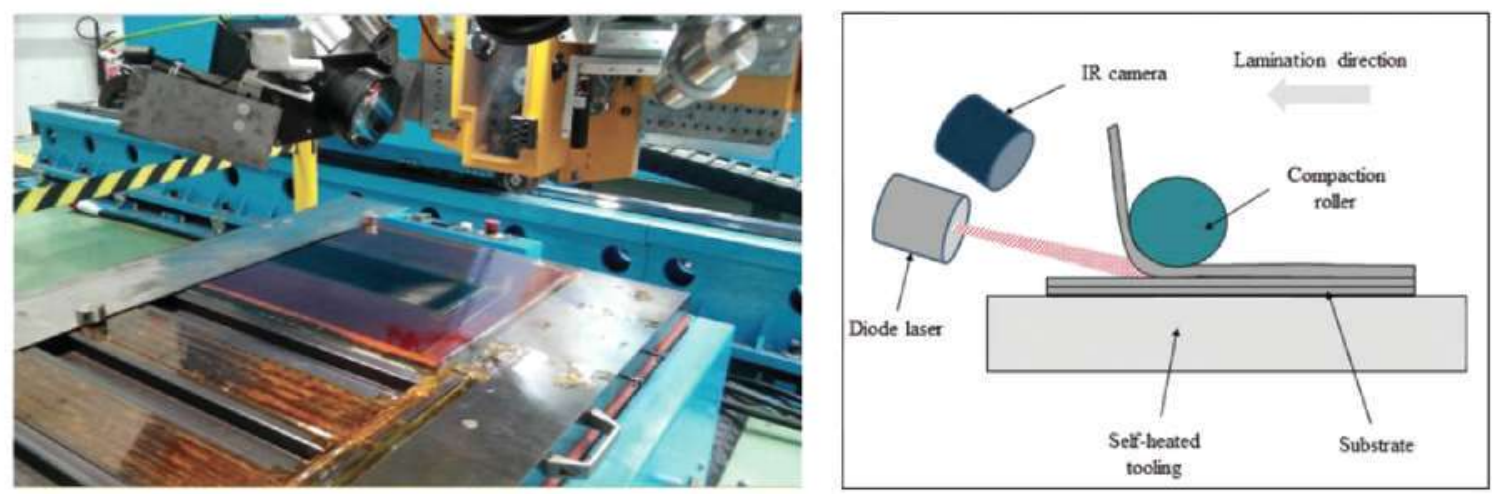

Figure 3. ISC manufacturing: lamination set-up (left). Scheme of the manufacturing process (right).

are compiled in Table 1 and were selected based on previous authors' experience for an optimal laminate manufacturing. ${ }^{17,44}$ Thus, tool temperature was kept at $200^{\circ} \mathrm{C}$, deposition rate was fixed at $2 \mathrm{~m} / \mathrm{min}$, the laser worked at an averaged power of $180 \mathrm{~W}$ and the silicone compaction roller applied a force of $500 \mathrm{~N}$ which led to a final applied pressure of approximately $2 \mathrm{MPa}$. The processing temperature was recorded real-time with an infrared thermal camera supplied by FLIR. A detail of the ISC process is given in Figure 3.

\section{Ultrasonic NDT}

All the manufactured specimens were submitted to ultrasonic NDT using automated TRITON 8000 TT+ equipment supplied by Tecnitest (Spain). A double through-transmission method was applied in a water tank with a reflector plate. A single transducer was used, working as transmitter-receiver. A typical frequency of $5 \mathrm{MHz}$ was chosen to inspect all the specimens. The equipment's software generated C-scan registers which were analysed for the study of defects such as porosity or voids. The generated $\mathrm{C}$-scans can be studied in different modes, including amplitude and attenuation (in $\mathrm{dB}$ ).

\section{Differential scanning calorimetry}

DSC tests were performed to obtain thermograms and degree of crystallinity of all the specimens. At least three different specimens of different regions of each laminate were tested, with a mass of at least $15 \mathrm{mg}$. DSC tests were conducted according to ISO 11357-3 in a calibrated Q2000 equipment from TA Instruments. ${ }^{45}$ Dynamic tests were performed with a heating rate of $20^{\circ} \mathrm{C} / \mathrm{min}$ up to $390^{\circ} \mathrm{C}$ starting from room temperature; followed by a 5-min isotherm. Cooling was then performed at a rate of $10^{\circ} \mathrm{C} / \mathrm{min}$. The degree of crystallinity $X$ was calculated using expression (1)

$$
X=\frac{\Delta H_{m}-\Delta H_{c}}{\Delta H_{f}(1-\alpha)}
$$

where $\Delta H_{m}$ is the enthalpy of fusion at melting point, $\Delta H_{c}$ is the enthalpy of cold crystallization (which can be observed in some cases), $\Delta H_{f}$ is the enthalpy of the completely crystalline polymer (considered as $130 \mathrm{~J} / \mathrm{g}$ ) and $\alpha$ refers to the weight fraction of carbon fibre within the laminate. Experimental values of weight 
fibre fraction obtained after matrix digestion testing were applied to determine the degree of crystallinity.

\section{Void content assessment}

Matrix digestion. The void content of all laminates was calculated by matrix digestion method, following EN $25644^{46}$ A minimum of three samples from different regions of each laminates were subjected to evaluation. The density of each sample is calculated before the digestion of the matrix with sulphuric acid. The weight of the coupon was then compared before and after the matrix removal in order to obtain the void content of the sample.

$X$-ray micro-CT. One specimen with approximate dimensions $10 \times 10 \mathrm{~mm}$ was extracted from each laminate and scanned using a Bruker SkyScan 1172 X-ray Micro-CT Scanner located at the University of Auckland Bioengineering Institute. The coupons were extracted from the central part of the laminates in order to avoid edges effects. The settings used for the scans are provided in Table 2 .

The X-ray projections obtained from the scans were reconstructed using NRecon version 1.6.9.18 using the InstaRecon version 2,0.3.7 engine into 16-bit threedimensional volumes split into equally spaced TIFF image sequences. The reconstructed data were reoriented to align the $x, y$ and $z$ planes to the actual specimen orientation and their histograms were stretched to provide adequate contrast using ImageJ. ${ }^{47}$ Uneven greyscale intensities between the specimen centres and edges were corrected using fast Fourier transform filter within ImageJ before converting the adjusted image sequences into 8-bit formats. The image sequences were then processed to quantify the void morphology and locations using the method proposed by Ramesh et al. ${ }^{40}$ The image processing involved stretching the histogram of the reconstructed volume to improve contrast and binarizing the volumes by applying an adaptive threshold to isolate the voids

Table 2. Micro-CT scan settings.

\begin{tabular}{ll}
\hline Parameter & Value \\
\hline Voxel size & $4.47 \mu \mathrm{m}$ \\
Source voltage & $85 \mathrm{kV}$ \\
Source current & $118 \mu \mathrm{A}$ \\
Specimen to source distance & $106.93 \mathrm{~mm}$ \\
Camera to source distance & $215.234 \mathrm{~mm}$ \\
Exposure time & $600 \mathrm{~ms}$ \\
Rotation step & $0.20^{\circ}$ \\
Total rotation & $360^{\circ}$ \\
Frames per projection & 2 \\
Shuttling/random movement & Yes \\
\hline
\end{tabular}

before removing any residual noise. Finally, the locations, shapes and sizes of voids were quantified for all six specimens.

\section{Mechanical testing}

One of the main purposes of this work was to compare the mechanical response of TP-AFP laminates with other manufacturing by more conventional methods, as oven or hot-press. With this aim, a variety of mechanical tests were selected to evaluate the behaviour of the manufactured laminates. The testing included both fibre and matrix-dominated mechanical testing. This selection was made due to the fact that intrinsic differences in the manufacturing processes may lead to different irregularities in the matrix (such as degradation or high porosity), but also may result in detrimental effect on the fibre contribution, such as waviness or misalignment. The selected testing consisted of tensile (EN 2561, type A), flexure (EN 2562, type B), in-plane shear strength (IPSS; EN 6031) and ILSS (EN 2563). Batches containing a minimum of six coupons were tested for each mechanical testing. All coupons were machined to final dimensions by means of a diamond wheel.

ILSS. Nominal specimen dimensions of ILSS coupons were $20 \times 10 \times 2.16 \mathrm{~mm}$ with $[0]_{16}$ stacking. Cross-head stroke was $1 \mathrm{~mm} / \mathrm{min}$. The peak load was recorded during the test as a function of displacement. Maximum load at first failure was also recorded. The apparent ILSS could then be calculated.

IPSS. For IPSS testing, nominal dimensions $230 \times 25 \times 2.16 \mathrm{~mm}$ coupons with $[+45 /-45]_{4 \mathrm{~s}}$ lay-up were used. Load was applied at a rate of $1 \mathrm{~mm} / \mathrm{min}$, and the longitudinal and transversal strains were continuously recorded with extensometers for each test. When a longitudinal strain of $2 \%$ was reached, the cross-head speed was increased to $10 \mathrm{~mm} / \mathrm{min}$ until failure. Maximum load was recorded to calculate the ultimate IPSS $\tau_{12}$. The IPS modulus was also calculated.

Tensile. Nominal dimensions of tensile coupons were $250 \times 2 \times 2.16 \mathrm{~mm}$ with a $[0]_{16}$ lay-up. During the test, the load was applied at a constant rate of $2 \mathrm{~mm} / \mathrm{min}$, while recording strain in the longitudinal direction with an extensometer. Load at failure was also recorded for the calculation of tensile strength.

Flexure. For flexure test, type B coupons with dimensions $100 \times 10 \times 2.16 \mathrm{~mm}$ and a unidirectional $[0]_{16}$ layup were used. A cross-head speed of $5 \mathrm{~mm} / \mathrm{min}$ was used during testing. Deflection as a function of load 
and load at failure were recorded during the test, in order to calculate flexural strength and modulus.

\section{Results and discussion}

\section{Ultrasonic NDT}

Quality control by means of ultrasonic testing was performed, and the resulting $\mathrm{C}$-scans of laminates are shown in Figure 4 with the corresponding attenuation scale (in a grey scale showing attenuation in $\mathrm{dB}$ ). Black squares are due to methacrylate supporting tools. If all $\mathrm{C}$-scans are evaluated following typical aerospace thresholds corresponding to an attenuation of $6 \mathrm{~dB}$ and a minimum defect size of $6 \times 6 \mathrm{~mm}$, all the laminates may be considered as defect-free, except those manufactured by ISC. Vertical lines appearing in laminate VBO_0 (in contrast with laminate HP_0) were caused by surface geometrical effects in the inspection. Typically, laminates manufactured by VBO have a more irregular surface finish than laminates produced by hot-press, mainly owing to the lack of caul plates in VBO manufacturing. Thus, the surface geometrical irregularities caused slight reflection of the ultrasonic waves. Attenuated areas can be observed in both ISC laminates, corresponding to the regions where the incoming tow is cut and the tensile load applied by the spool engine is lost during lamination. Those areas were avoided for the trimming of coupons. Space between tapes can be also found more attenuated in C-scans of ISC laminates.

\section{Differential scanning calorimetry}

The results provided by the DSC testing revealed the degree of crystallinity of the laminates manufactured during this study, which are compiled in Table 3. Figure 5 shows the representative DSC thermograms performed to samples manufactured with the different methods under study. The in situ consolidated laminates presented a slightly lower degree of crystallinity $(36.9 \%)$ than the laminates manufactured by the rest of OoA methods, which showed a degree of crystallinity higher than $40 \%$. Final degree of crystallinity of thermoplastic components is mainly related to the cooling rate of the manufacturing process, therefore fast cooling rates during ISC are the main cause of lower degrees of crystallinity in the ISC manufactured laminates. During ISC manufacturing, fast cooling rates above $10,000^{\circ} \mathrm{C} / \mathrm{min}$ may take place, which is very different to the cooling rates considered optimal of $1-5^{\circ} \mathrm{C} / \mathrm{min}$ to achieve full crystallization. However, previous experience of the authors using unheated tooling during lamination resulted in lower values of degree of crystallinity. Although the ISC panels presented

Table 3. Degree of crystallinity results of manufactured laminates.

\begin{tabular}{lll}
\hline $\begin{array}{l}\text { Manufacturing } \\
\text { process }\end{array}$ & $\begin{array}{l}\text { Degree of } \\
\text { crystallinity (\%) }\end{array}$ & $\begin{array}{l}\text { Relation to } \\
\text { VBO (\%) }\end{array}$ \\
\hline VBO & $40.1 \pm 0.2$ & - \\
Hot-press & $42.7 \pm 6.3$ & 107 \\
ISC & $36.9 \pm 2.8$ & 92 \\
\hline
\end{tabular}

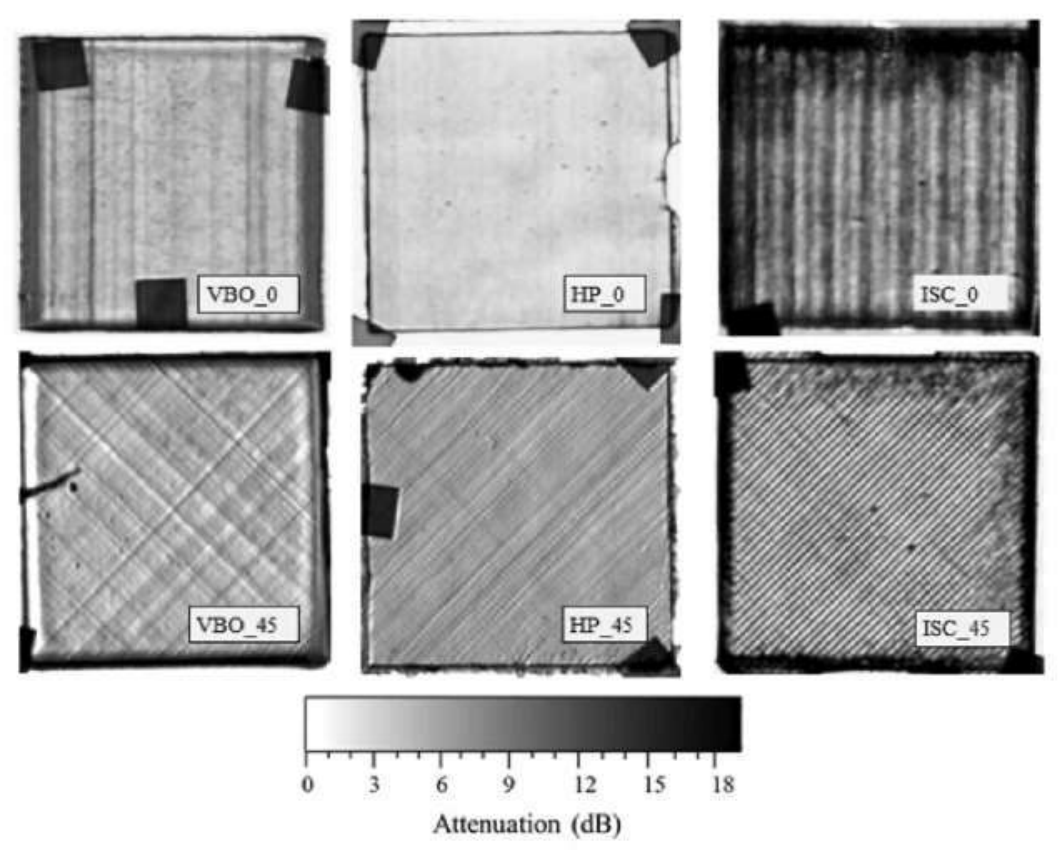

Figure 4. Ultrasonic C-scans of manufactured specimens by VBO, hot-press and ISC. 


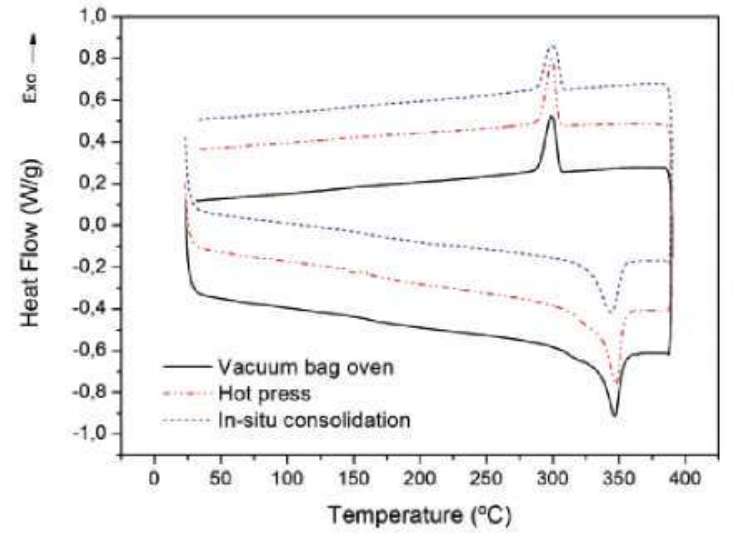

Figure 5. DSC thermograms of samples manufactured by different manufacturing methods including AFP in situ consolidation, vacuum bag in oven and hot-press.

lower degree of crystallinity, it is worth noting that none of these panels displayed the cold crystallization event, and therefore the lower value of crystallinity could also be associated with different crystallization developments in comparison with OoA panels. Moreover, as it can be appreciated in Figure 5, outof- autoclave laminates exhibited multiple melting peaks which can be related with two distinct crystal morphologies or with a melting and recrystallization phenomenon. ${ }^{46}$

These previous results match with the values reported by other authors as Comer et al., ${ }^{8}$ who reported a crystallinity of $17.6 \%$ in their laser-assisted AFP laminates manufactured using unheated tooling. Tierney and Gillespie ${ }^{28}$ determined the degree of crystallinity of a consolidated tape to be in the range of $10-29.5 \%$ also using an unheated tooling. By performing this comparison, it can be deducted that the use of heated tools can significantly increase the final crystallization of the part. It is well known that the degree of crystallinity is related to the final mechanical behaviour of thermoplastic composite structures. The mechanical properties of the laminates in this study may not be affected by a low degree of crystallinity in the case of in situ consolidated laminates, since their crystallinity is above the crystallinity threshold of $35 \%$ - which is the established threshold reported by Gao et al. ${ }^{31}$ from which the mechanical properties and chemical resistance can be considered as optimal.

\section{Void content analysis}

Matrix digestion. Figure 6 shows the results of the matrix digestion testing performed for void content assessment of each laminate. The results suggest that those laminates that were fabricated by ISC had a level of

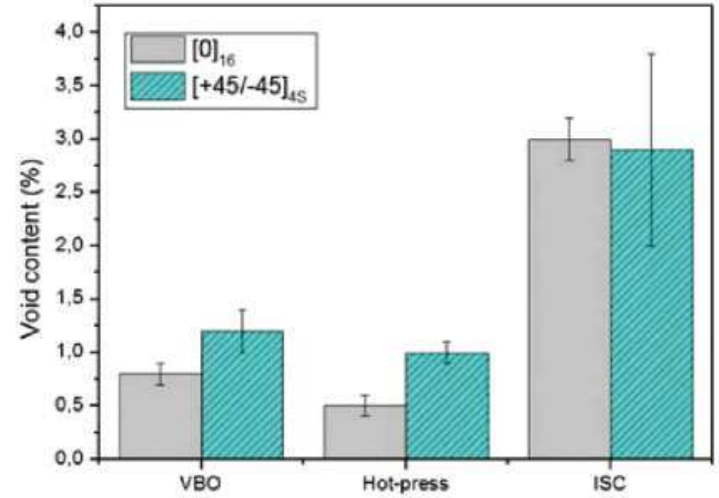

Figure 6. Void content values of the manufactured laminates for this study, including $[0]_{16}$ and $[+45 /-45]_{4 S}$ lay-ups manufactured by the three OoA methods used in this study.

porosity around $3 \%$, meanwhile laminates manufactured by VBO or hot-press resulted in a porosity range of $0.5-1.2 \%$. Depending on the aerospace application, the void content threshold may vary between $1 \%$ and $2 \%{ }^{48}{ }^{50}$ For other specific applications, a higher porosity level may be accepted, up to $5 \%{ }^{49,51}$ Also, it has been previously reported that thermoplastic composites can be tougher than thermoset, even at high void volume content. ${ }^{52}$ In this study, values below $2 \%$ of porosity were considered optimal. Regarding matrix content by weight, an average value for each manufacturing process was assessed. The results consisted in $35.2 \pm 3.8 \%$ for VBO, $36.0 \pm 0.9 \%$ for hotpress and $33.3 \pm 0.1 \%$ for ISC. All the laminates presented values within $34 \pm 5 \%$ of matrix content, which are in agreement with the values reported in the material supplier data sheet.

Typically, OoA manufacturing methods are associated with high porosity. However, two of the manufacturing processes presented in this study (VBO and hot-press) showed porosity levels which can be considered equivalent to autoclave levels. This is only possible if a good combination of key manufacturing parameters are applied, combining proper levels of consolidation temperature, pressure and dwell time which allow a correct void diffusion and compression during the consolidation process. Zhang et al. ${ }^{22}$ developed a void filling model which determined that a dwell time of 11 min should be enough for obtaining a voidfree laminate manufactured in oven. The dwell times applied in this study were 15-20 min for both hot-press and oven cycles, which correlates well with the reported dwell times by Zhang et al. However, larger or more complex structures than those fabricated in this study may need longer dwell times for a correct void extraction in VBO and press processes. 
On the other hand, thermoplastic laminates manufactured via ISC showed a significant higher void volume fraction: around $3 \%$. The fact that the laminates manufactured under this technology resulted in higher porosity laminates is mainly related to the manufacturing process itself and the void reduction mechanisms. Optimal consolidation dwell times can be applied in oven and hot-press, when the consolidation temperature is held above the PEEK melting point in order to facilitate the evacuation of the air trapped at intralaminar locations (within the raw prepreg tape) and interlaminar region (related to the intimate contact). During the dwell time, the resin is usually at its lower viscosity level, so void reduction mechanisms such as migration or diffusion assisted by vacuum or hot-press pressure may take place. ISC process is significantly different, since the main phenomena occur at ultra-short times. In this study, a tape speed of $2 \mathrm{~m} / \mathrm{min}$ was applied with a laser heating profile length of 130 $140 \mathrm{~mm}$, resulting in the application of heat during several milliseconds, followed by a fast cooling down, up to $10,000^{\circ} \mathrm{C} / \mathrm{min}$. The main manufacturing parameters (lamination speed, compaction force and laser power) should be completely optimized for proper void removal during ISC, which is a challenging task. Free-void structures could be achieved by having a good degree of intimate contact and an optimal void evacuation, which are again mainly driven by the roller force, laser temperature and speed. The quality of the raw prepreg material has been also reported to have a great impact on the final quality of the samples. ${ }^{33}$ Good parallelism between the faces of thermoplastic prepreg tows is essential for an optimal lamination, but also a good distribution of fibres is required. A micrograph representative of the thermoplastic raw tape used in this study is shown in Figure 7, where intralaminar voids, poor fibre and matrix distribution and uneven surfaces can be found. It is thought that the

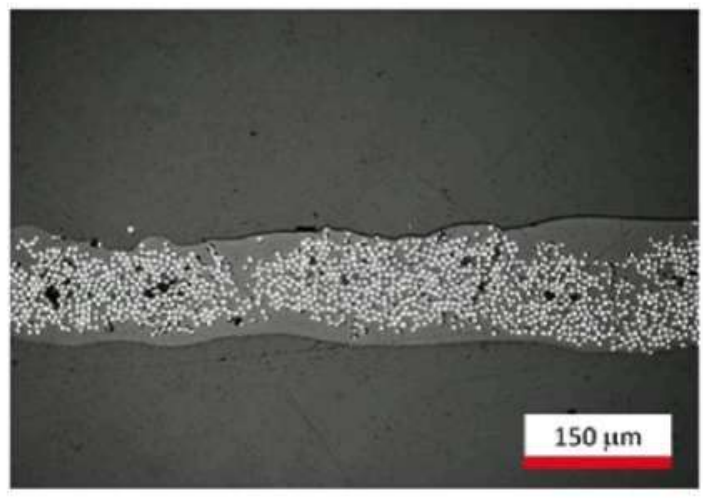

Figure 7. Photomicrograph of the APC2/AS4 tapes used in this study for the ISC laminates manufacturing. development of appropriate materials grades by material suppliers may be of great assistance in the achievement of higher mechanical response. Other authors reported similar porosity levels to those reported in this study. For instance, Tierney and Gillespie ${ }^{28}$ reported up to $4 \%$ of void content in in situ consolidated samples and Comer et al. ${ }^{8}$ declared a void content of $2.83 \%$ in their samples, determined by $2 \mathrm{D}$ microscopy. Other effects such as re-pass, void rebound or the tool temperature have an impact on the final void content of ISC structures, but it will be further discussed in the next sub-section, where the results of micro-CT are presented.

3D X-ray computed tomography. The micro-CT analysis allowed a deeper study to be undertaken of the porosity within the structures, including void distribution, size and shape.

Figure 8 shows the 3D reconstruction and the void extraction process (voids highlighted in red) for the VBO_45 and ISC_45 samples. The figure depicts the homogeneous distribution of very small voids in the VBO sample while it shows the accumulation of large voids in the upper layers for the ISC sample.

The distribution of voids through the thickness can be found in Figure 9, where the porosity of each sample is plotted against the thickness. In line with the matrix digestion results previously discussed, the ISC laminates contained larger porosity than the laminates manufactured by other manufacturing techniques. However, in this case, the figure suggests that the porosity of ISC laminates is mainly located at interlaminar positions, according to the peaks appearing in the graph. Regarding the stacking sequence of ISC laminates, the voids are equally distributed between the layers across the thickness of ISC_ 0 sample, meanwhile the voids are accumulated in the outer five plies of ISC_45. A homogeneous low porosity was found for both hot-pressed laminates in contrast with VBO laminates, where HP_45 showed slightly larger porosity. As mentioned in the previous section, values under $2 \%$ were considered optimal.

The accumulation of voids in upper layers in ISC laminates has been previously discussed in the literature and it has been related to the fact that the external plies are consolidated a fewer number of times compared to the bottom layers. ${ }^{17,28}$ Van Hoa et al. ${ }^{12}$ proposed a re-pass method which may assist in the reduction of voids accumulation in the external layers. Re-pass method is based on extra compaction roller and laser cycles without material feeding. In addition to the difference in the number of consolidation passes, other factors can affect the voids distribution in ISC manufacturing. In this way, when the substrate material gets thicker during the lamination 
(a)

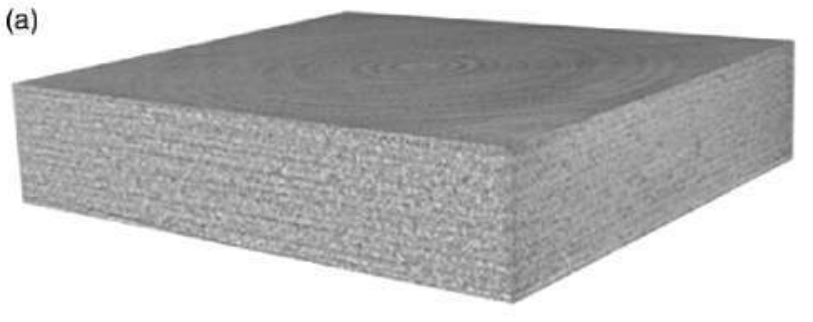

(c)

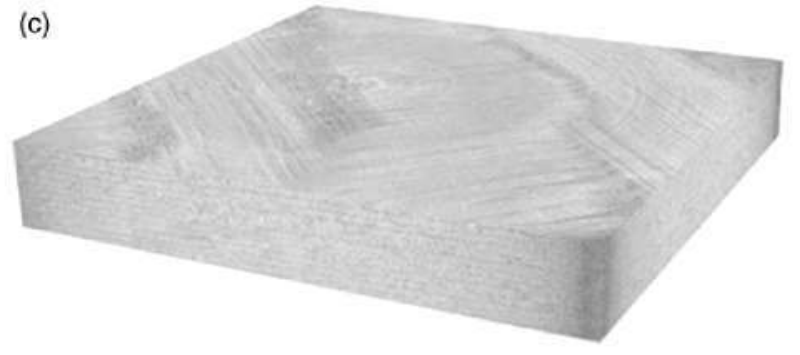

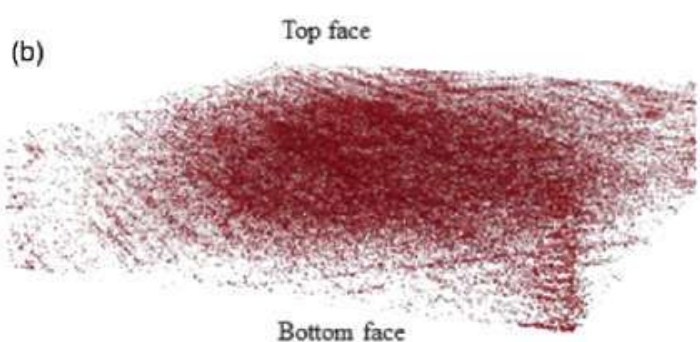

(d)

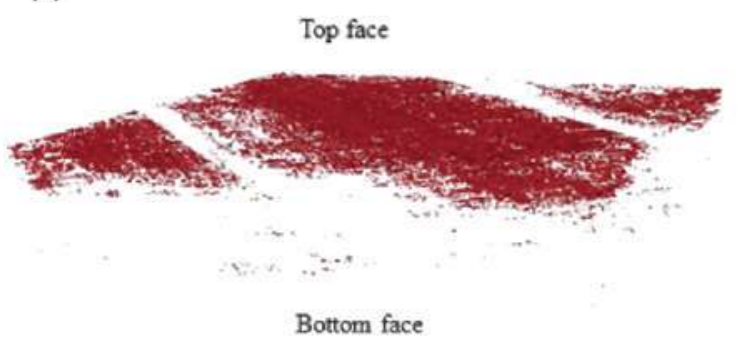

Figure 8. 3D reconstruction of scans and void extraction (voids highlighted in red): (a) 3D reconstruction of VBO_45 sample and (b) its corresponding void extraction; (c) 3D reconstruction of ISC_45 sample and (d) its corresponding void extraction.
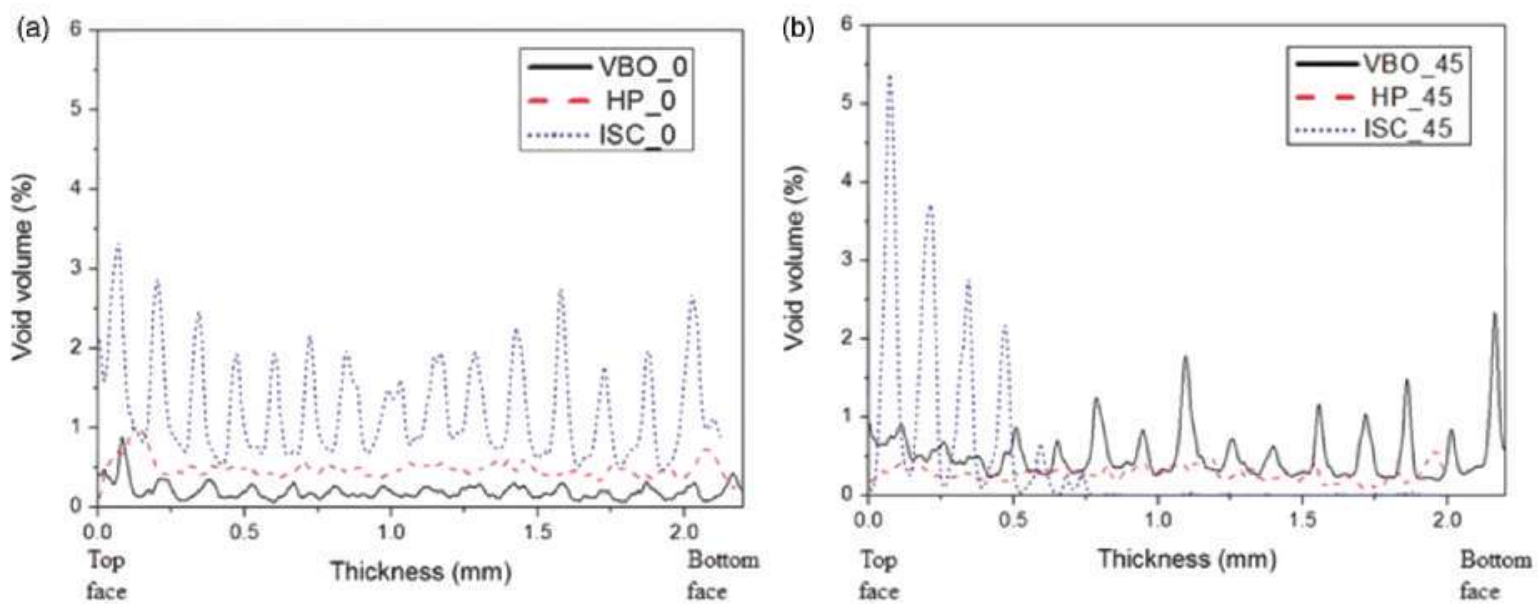

Figure 9. Distribution of voids across the thickness. (a) Void volume fraction versus thickness in all samples with stacking sequence $[0]_{16}$ and (b) void volume fraction versus thickness in all samples with stacking sequence $[45 /-45]_{45}$.

process, the heat may be retained by the composite causing slower cooling down and facilitating a void rebound effect. ${ }^{8}$ In that case, the voids which were compressed by the roller may suffer an expansion if the temperature is high enough after the pressure from the roller is lost.

A quantitative study of the void size was also performed and the results are shown in Figure 10, where the number of voids related to their size is represented. The results suggest that the amount of very small voids is similar for the laminates manufactured by all the manufacturing methods and there is a clear decreasing trend of the voids number with the void size. However, it can be clearly observed that the ISC samples have larger voids than the laminates manufactured by VBO or hot-press. Large voids may act as stress concentrations $^{53}$ and can lead to an early failure impacting the final properties of the final material. Thus, void distribution and size may play a key role, leading to a decrease in the final mechanical properties of the ISC laminates. The mechanical response of all laminates is presented and discussed in the next section.

In addition to the void distribution and size, microCT analysis allowed the study of void shape. In this case, a more qualitative result is shown in Figure 11, where the average intensity projections through the thickness for ISC samples in the plane $X Y$ are presented. Thus, the energy attenuation through the 


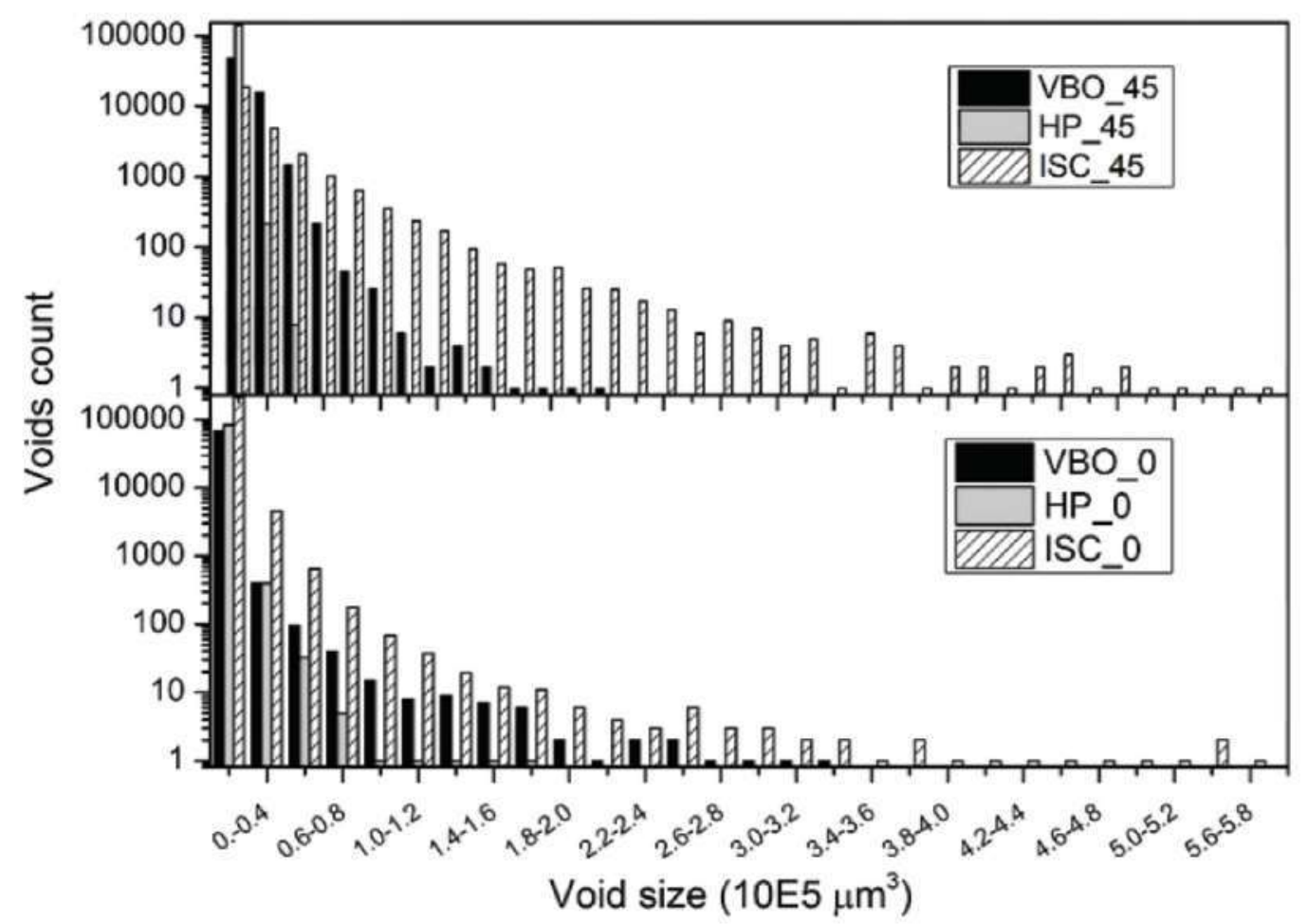

Figure 10. Void count as a function of void size for all the laminates manufactured in this study: $[45 /-45]_{4 S}$ samples (top) and $[0]_{16}$ samples (bottom).
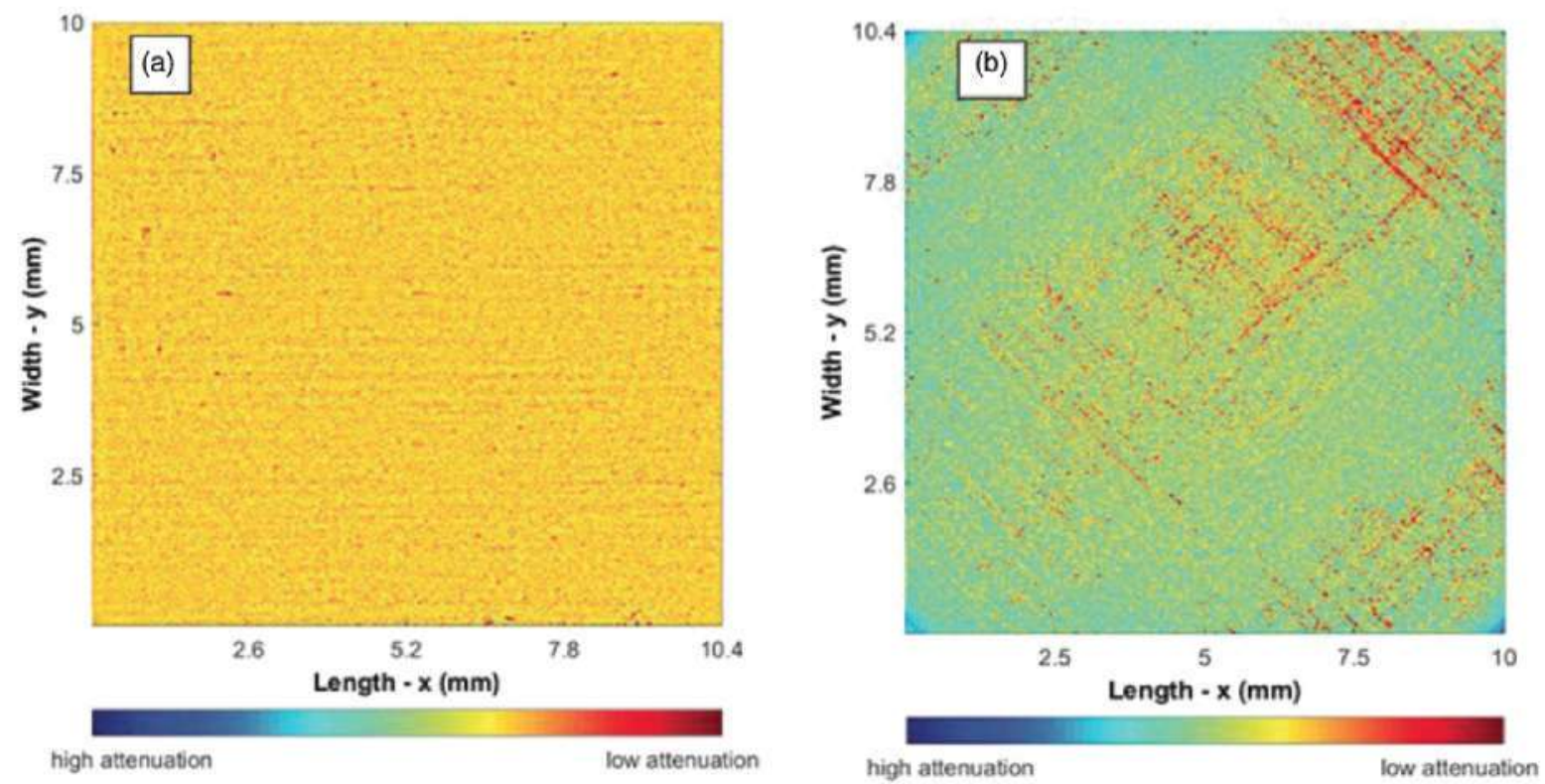

Figure II. Projection of the porosity in the $X Y$ plane for samples: (a) ISC_0 and (b) ISC_45.

thickness was plotted. The figure is presented with an attenuation scale, corresponding to the attenuated $\mathrm{X}$-ray energy. Less attenuated regions correspond to void locations. The projections were colourized to highlight the overall shapes of voids represented by regions of low attenuation. It can be observed from the figure that the voids tend to be located along the fibre direction, as also reported by other authors as Hernández et al. ${ }^{38}$ 


\section{Mechanical testing}

In this section, the results of all the performed mechanical testing are presented and discussed. In general terms, laminates manufactured in oven and hot-press presented similar results with minimal variations, meanwhile the laminates manufactured by ISC exhibited lower strength values compared to the oven reference. The results of each mechanical testing are discussed in detail hereunder.

ILSS. Interlaminar shear (ILS) testing is a widely used screening mechanical test mainly due to low material and time consumptions. During the ILS testing, the applied loads are expected to generate transverse shear stresses in the coupon, which will eventually cause an interlaminar failure. The ILS results of this study are compiled in Table 4 and the representative load-displacement curves are presented in Figure 12(a). The ILSS value obtained for the ISC laminate was $71 \mathrm{MPa}$, which was considerably lower than the ILSS values obtained from VBO (107 MPa) and hot-press consolidation $(109 \mathrm{MPa})$. The ILSS values of VBO and hot-press laminates are at the same standard as the APC2-AS4 autoclaved ILSS values (105 MPa) reported by Lamontia et al., ${ }^{54}$ underlining in this way

Table 4. Interlaminar shear properties (ILSS) of thermoplastic composites manufactured by different OoA methods.

\begin{tabular}{llll}
\hline Mechanical property & VBO & Hot-press & ISC \\
\hline ILSS & & & \\
Strength (MPa) & $107 \pm 3$ & $109 \pm 8$ & $71 \pm 2$ \\
Peak load (N) & $3316 \pm 74$ & $3362 \pm 227$ & $2228 \pm 59$ \\
Comparison & - & 102 & 66.2 \\
$\quad$ to VBO (\%) & & & \\
\hline
\end{tabular}

that ILSS autoclave levels can be achieved via OoA techniques.

For a correct understanding of the drop of ILSS value in ISC manufactured laminates corresponding to a $34 \%$ compared to the VBO reference, it is important to note that ILS is a matrix-dominated testing which has been proven to be very sensitive to composites manufacturing defects, especially voids and porosity. ${ }^{55}$ Even if the reason behind this downfall may not respond to just a single reason, it is likely that the void content, distribution and size of ISC laminates discussed in the Void content analysis section played a dominant role in the question. Crystallinity is the other factor which is commonly related with the mechanical behaviour of thermoplastic composites, but its negative impact was previously discarded in this study due to the achievement of degrees of crystallinity above $35 \%$ in all the ISC laminates, owing mainly to a low lamination speed and the use of heated tooling.

The higher void content of ISC laminates $(3 \%$ in comparison with $1.2 \%$ or less in the VBO references) had a significant negative impact on the shear behaviour of the laminate. However, the high averaged void content may not be the main reason of the ILSS drop, since void distribution and void size have been proved to have a great impact on the mechanical response of composite materials. The tomography analysis determined that there was an accumulation of larger voids at the interlayers of ISC laminates, especially in the outer layers. Those results may lead to an early critical shear failure manly owing to the interlaminar voids accumulated between layers, which caused poor adhesion and consolidation. Figure 12(a) supports this assumption since an earlier failure may be observed in the load-displacement curves for the ISC specimens (a)

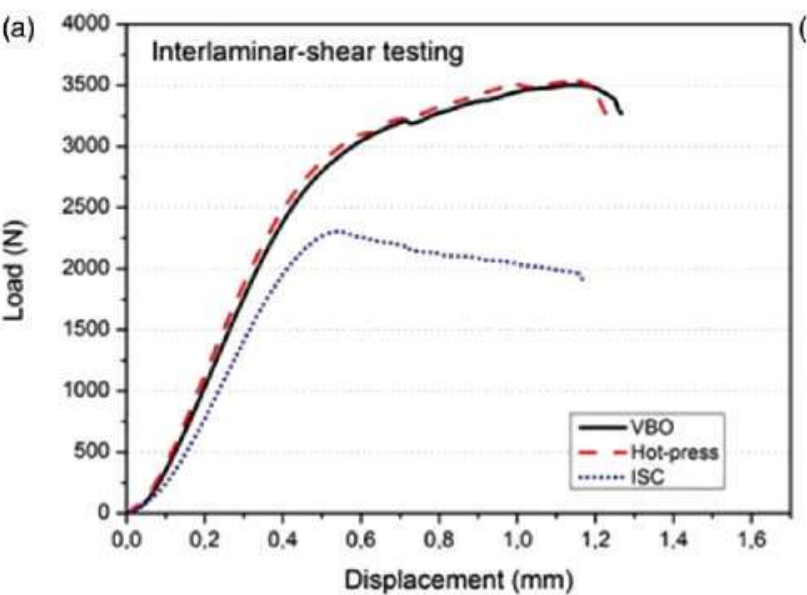

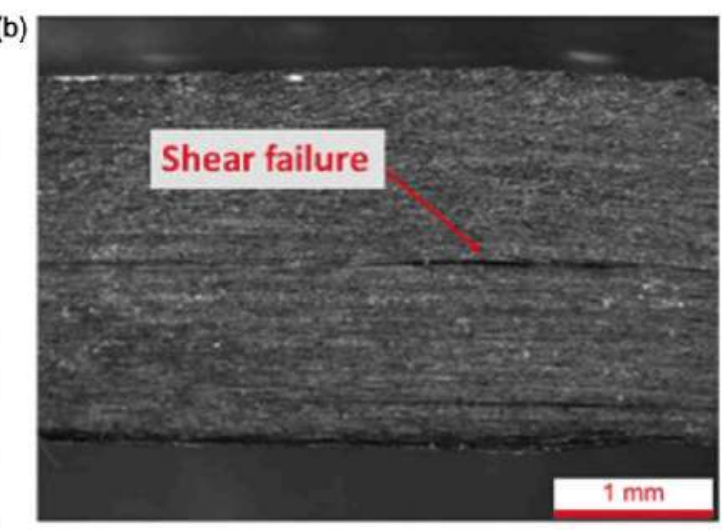

Figure 12. ILSS testing results: (a) load-displacement representative curves of interlaminar shear testing performed to thermoplastic laminates manufactured by VBO, hot-press and ISC; (b) detail of critical failure of ILSS coupons: interlaminar crack can be observed in the middle region of the coupon caused by shear stress during testing. 
compared with the oven and hot-press laminates. All the laminates performed similarly at low load levels where linear (elastic) behaviour was observed followed by an early failure in the case of ISC laminate. Nonetheless, plastic behaviour before failure was observed in the laminates corresponding to the other two manufacturing methods suggesting that the final failures were a combination of ILS and plastic deformation. ISC coupons did not experienced plastic deformation due to the early failure caused by interlaminar voids, preventing the coupon from plasticizing.

ILSS testing methods have been widely discussed for thermoplastic composites testing, since plastic deformation may occur leading to inaccurate calculation of ILSS values. A potential reduction of plastic deformation when thermoplastic composites are subjected to ILS testing was reported by Rosselli et al., ${ }^{1}$ who proposed a ILS device consisting in a modification from the SBS testing causing pure shear loads and therefore avoiding plasticization. The fact that plastic deformation may take place during ILS testing of thermoplastic composites makes it necessary to resort to another matrix-dominated testing such as IPS stress. For these tests, the ILSS failure mode was investigated revealing ILS fracture in all the specimens despite of possible plastic deformation, as depicted in Figure 12(b).

These results suggest that higher ILSS values closer to the autoclave reference could be reached by ISC laminates if the manufacturing process is optimized and the interlaminar voids were reduced. Also, an improved raw material quality with constant thickness and low intralaminar void content may facilitate the intimate contact and the void removal as reported in Gruber et al. ${ }^{33}$ Higher tool temperatures may also assist to improve the mechanical properties, as the case of Schledjewski and Miaris, ${ }^{32}$ who reported a value of ILSS of $89.16 \mathrm{MPa}$ working in a heated tool at $276^{\circ} \mathrm{C}$, which is considerable higher than the tool temperature used in this study.

IPSS. IPS testing together with ILS testing was the matrix-dominated testing performed in this study for the mechanical characterization of $\mathrm{CF} / \mathrm{PEEK}$ laminates. IPS testing consists of a $[45 /-45]_{n}$ coupon subjected to tensile loads in order to minimize the contribution of the fibre reinforcement so the critical failure is expected to occur within the matrix. Thus, IPS testing is presented as a good choice for the optimization study of a given manufacturing process which involves matrix consolidation and void removal. Even if the matrix plays the dominant role, there is an unavoidable fibre contribution during the testing, especially when the tensile loads may re-orient the carbon fibres through the test. The IPS results obtained during the experimental characterization are compiled in Table 5, and the representative load-displacement curves are depicted in Figure 13. In this case, the IPSS value of the hot-press laminate (180 MPa) slightly differed from the VBO reference (222 $\mathrm{MPa})$, resulting in a reduction of $19 \%$.

The IPSS value obtained from VBO manufacturing was especially high and it was even higher than autoclave levels reported by other authors as Gruber et al. ${ }^{33}$ who reported a CF/PEEK autoclaved IPSS value of $174 \mathrm{MPa}$, which is in line with the results of our hot-pressed laminate. Both IPSS values of VBO and hot-press laminates correspond to an optimal mechanical behaviour and therefore can be associated with defect-free laminates.

Regarding the ISC laminate, the IPSS value achieved in this study was $155 \mathrm{MPa}$, in accordance with Gruber et al., ${ }^{33}$ who reported an IPSS of $154 \mathrm{MPa}$ in ISC laminates. In our case, the IPSS value of ISC manufacturing method meant a drop of $30 \%$ of the IPSS in comparison with the oven

Table 5. In-plane shear properties of thermoplastic composites manufactured by different OoA methods.

\begin{tabular}{|c|c|c|c|}
\hline Mechanical property & VBO & Hot-press & ISC \\
\hline \multicolumn{4}{|l|}{ IPSS } \\
\hline \multicolumn{4}{|l|}{ Strength } \\
\hline Strength (MPa) & $222 \pm 4$ & $180 \pm 12$ & $155 \pm 2$ \\
\hline $\begin{array}{l}\text { Comparison to } \\
\text { VBO (\%) }\end{array}$ & - & 81 & 70 \\
\hline \multicolumn{4}{|l|}{ Modulus } \\
\hline Modulus (GPa) & $4.6 \pm 0.1$ & $4.3 \pm 0.1$ & $4.0 \pm 0.0$ \\
\hline $\begin{array}{l}\text { Comparison to } \\
\text { VBO }(\%)\end{array}$ & - & 94 & 87 \\
\hline
\end{tabular}

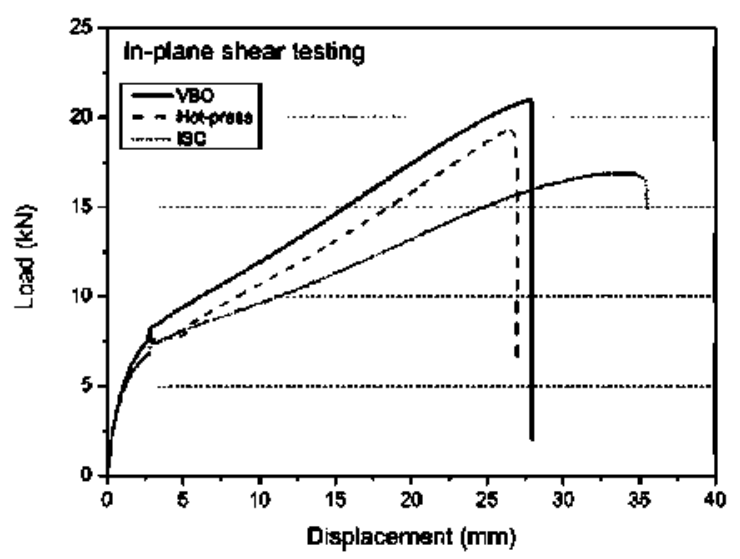

Figure 13. Load-displacement representative curves of in-plane shear testing performed to thermoplastic laminates manufactured by VBO, hot-press and ISC. 
reference. However, if the hot-pressed IPSS value was set as reference instead of the high VBO value, the drop of the IPSS value of the ISC laminate would correspond to $14 \%$. All the aspects discussed in the previous section of ILSS values of ISC laminates may be extrapolated here. Again, the void distribution observed for the ISC laminates are likely to have played an important role. Large elongated voids allocated in the fibre direction as observed in the 3D X-ray computed tomography section may weaken the fibre-matrix adhesion therefore facilitating matrix crack and leading to an early critical failure. If the load-displacement curve is observed in Figure 13, the critical failure may be detected at a lower load level in the case of the ISC coupons. A more ductile behaviour in the ISC coupon can be also deducted from the figure attributed to a larger plastic region. A ductile behaviour is characteristic of the amorphous state of the polymer and may be associated with the slightly lower degree of crystallinity of ISC laminates observed in the DSC results. Again, higher quality raw tapes could improve the mechanical response of ISC laminates.

Tensile. The results of the tensile testing of the thermoplastic laminates are presented in Table 6 and the representative load-displacement curves are shown in Figure 14. Tensile testing is mainly governed by the behaviour of the fibres and an explosive fibre breakage critical failure is expected to occur during testing. Similar values of tensile strength can be observed for the VBO $(2127 \mathrm{MPa})$ and hot-press (2228 MPa) laminates, meanwhile a lower value was achieved by the ISC laminate $(1847 \mathrm{MPa}$ ) meaning a $17 \%$ drop related to the VBO reference. As expected, tensile modulus did not experience significant variations depending on the manufacturing method. Even if tensile testing is considered a fibre-dominated mechanical testing, other authors reported a decrease of tensile strength with the void content of the tested laminates. Liu et al. ${ }^{51}$ reported a tensile strength drop of $20 \%$ in laminates with $3 \%$ of void content, which is similar to our case. However, the drop of tensile properties may not be

Table 6. Tensile properties of thermoplastic composites manufactured by different OOA methods.

\begin{tabular}{llll}
\hline Mechanical property & VBO & Hot-press & ISC \\
\hline Tensile & & & \\
Strength & & & \\
Strength (MPa) & $2127 \pm 44$ & $2228 \pm 72$ & $1847 \pm 81$ \\
$\quad$ Comparison to VBO (\%) & - & 104.7 & 86.8 \\
Modulus & & & \\
Modulus (GPa) & $139 \pm 6$ & $144 \pm 3$ & $136 \pm 6$ \\
Comparison to & - & 103.6 & 97.8 \\
VBO (\%) & & & \\
\hline
\end{tabular}

attributed only to the void content, since other particular factors of the ISC manufacturing process may have affected the mechanical response. Other affecting factors may include the appearance of residual stresses in ISC manufactured laminates as well as in-plane waviness of the fibres. Residual stresses appearing in in situ consolidated thermoplastic structures have been discussed in the literature. Van Hoa et al. ${ }^{12}$ explained in how mismatches in thermal expansion coefficients in different directions of the tape, temperature gradient, shrinkage and crystallization can lead to final residual stresses in the final structure. Also in Van Hoa et al., ${ }^{12}$ the authors suggested a fabrication methodology to get rid of residual stresses based on the use of a heated tooling up to $250^{\circ} \mathrm{C}$ when working with $\mathrm{CF} / \mathrm{PEEK}$. They finally reported higher tensile strength in ISC laminates compared to autoclave. In this study, the authors also used a heated tooling up to $200^{\circ} \mathrm{C}$ during the lamination of ISC laminates but the effect of residual stresses could be still observed in the $[0]_{16}$ laminate. The a priori minimum difference of $50^{\circ} \mathrm{C}$ in the tool temperature could assist in the complete removal of residual stresses.

Flexure. Table 7 compiles the results of flexural strength and modulus, and Figure 15 depicts representative load-displacement curves of the tests. Critical failure is expected to occur by compression or tensile of the carbon fibres when flexural loads are applied. In this case, flexural strength of VBO and hot-press manufactured laminates were similar (1812 and $1856 \mathrm{MPa}$, respectively) and presented higher values than ISC laminate (1505 MPa). Regarding modulus, no significant variations of more than $5 \%$ were observed. The drop of flexure strength of ISC compared to the VBO reference corresponded to an approximately $17 \%$, meaning a smaller drop when compared to the previously ILSS

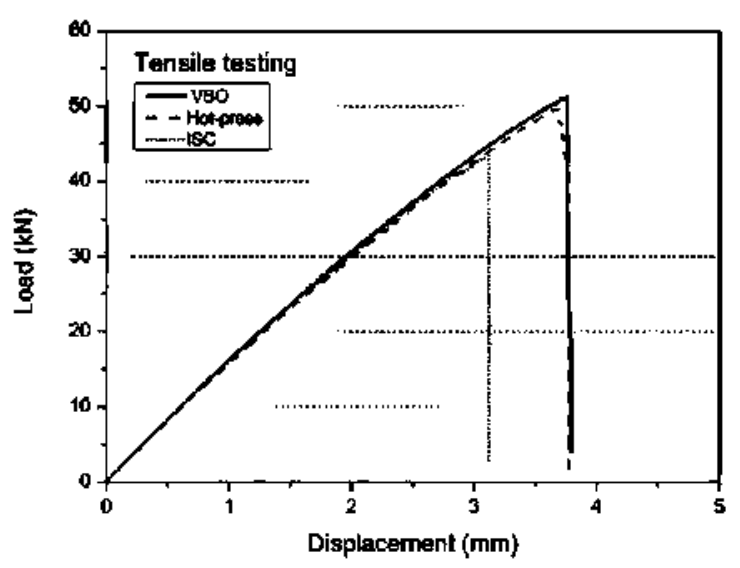

Figure 14. Load-displacement representative curves of tensile testing performed to thermoplastic laminates manufactured in oven, hot-press and TP-AFP in situ consolidation. 
and IPSS values. An early flexure failure of ISC samples can be observed in the representative load curves in Figure 15. The flexural results of ISC samples are mainly attributed to the void content and distribution found in the ISC specimens. Samples containing voids have been previously reported to perform worse during flexure testing, since voids at interlayer locations may facilitate the crack propagation. ${ }^{56}$ Thus, void content

Table 7. Flexural properties of thermoplastic composites manufactured by different OoA methods.

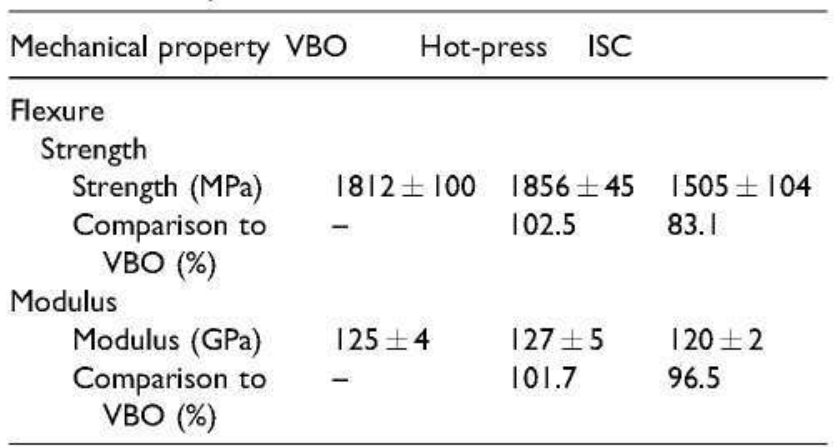

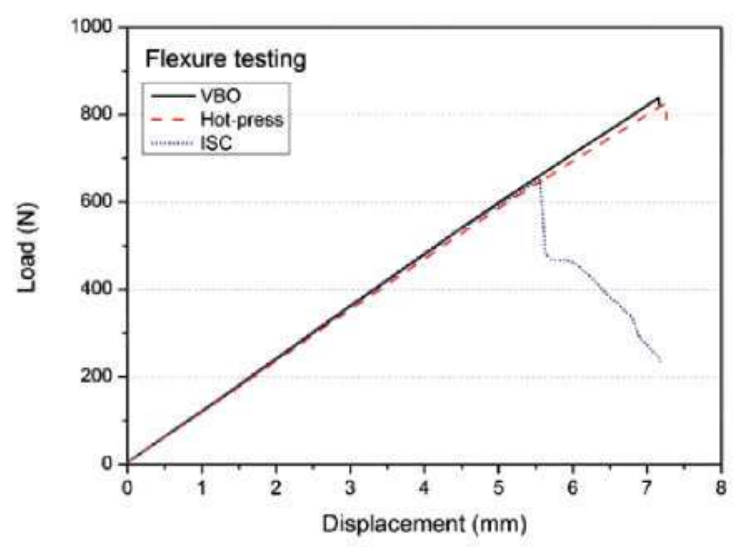

Figure 15. Load-displacement representative curves of flexure testing performed to thermoplastic laminates manufactured by VBO, hot-press and ISC. reduces the compressive modulus of the sample leading to the before commented early failure. The flexural results also matched the results of Liu et al., ${ }^{51}$ who reported a $22 \%$ drop of flexural strength in laminates with $3.2 \%$ of void content. In the load-displacement curve (Figure 15) a linear increase of stress can be observed in all samples followed by an early failure of ISC specimens, which then experienced a stepped reduction of stress until critical failure. The reduction of tensile and compression strength values in laminates with high void content ${ }^{51}$ explains the early critical failure in our ISC coupons. The stepped phenomenon is thought to occur due to first compressive damage of the top plies followed by a final tensile ultimate failure occurring in the bottom plies of the tested coupons. In the case of VBO and hot-pressed specimens, a sharp load drop was observed during the testing suggesting a sudden ultimate failure. Magnified images of the failure mode were taken (Figure 16) as evidence of valid flexure failure. Similar brittle failure behaviour was observed in the coupons of all laminates, which is indicative of similar values of crystallinity. By contrast, Comer et al. ${ }^{8}$ reported ductile failure during flexural testing of their ISC samples owing to a largely amorphous matrix.

\section{Conclusions}

In this work, a set of CF/PEEK laminates were manufactured by different OoA manufacturing methods including VBO, hot-press and an innovative laserassisted ISC. All the laminates were investigated with ultrasonic NDT, DSC, matrix digestion, X-ray micro$\mathrm{CT}$ and a set of mechanical tests including matrixdominated and fibre-dominated testing methods.

Ultrasonic scanning revealed very good quality of VBO and hot-press laminates meanwhile some attenuation patterns could be observed in ISC laminates. Matrix digestion testing determined that ISC laminates had average porosity values around $3 \%$ meanwhile VBO and hot-press laminates had levels of $1.2 \%$ or

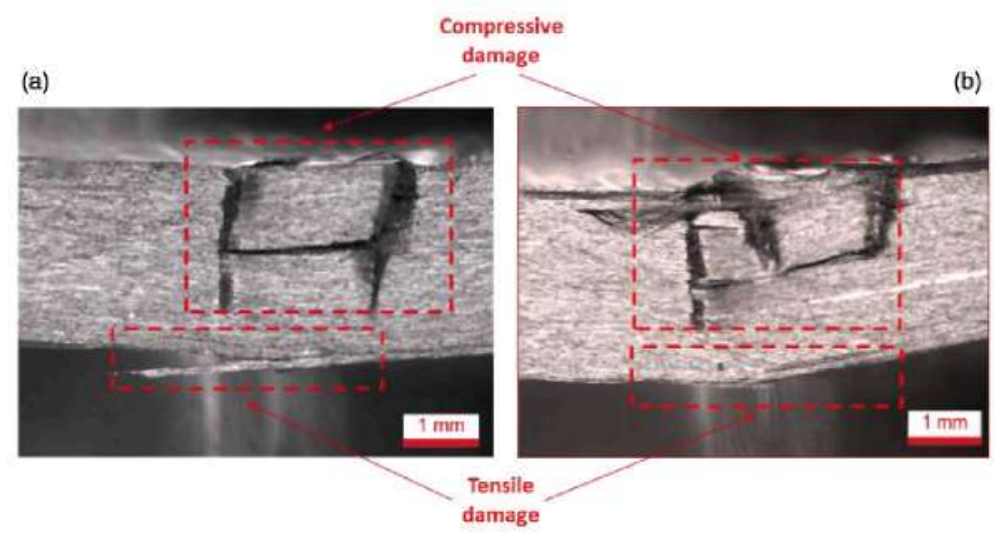

Figure 16. Magnified images of the flexure failure mode of (a) VBO manufactured coupon and (b) ISC coupon. 
less. Micro-CT imaging showed the distribution, size and shape of the voids, indicating that accumulation of larger voids in the upper layers may occur in ISC laminates in addition to having larger voids. Also, the voids were found to be primarily oriented in the fibre direction of the laminates. DSC analysis revealed satisfactory crystallinity levels over $35 \%$ in all the laminates, which should not compromise the mechanical response. This suggests that the use of self-heated tooling above $\mathrm{Tg}$ may result in proper crystallinity levels.

VBO and hot-press manufactured laminates showed similar results in all the mechanical properties except in the case of IPSS, where the VBO laminate reached an especially high value of $222 \mathrm{MPa}$, even when compared to autoclaved levels reported by Gruber et al. ${ }^{33}$ By contrast, ISC laminates exhibited lower values than the VBO reference: $66 \%$ of ILSS, $70 \%$ of IPS strength, $83 \%$ of flexure strength and $87 \%$ of tensile strength. Moduli values did not present large differences owing to similar crystallinity levels. The drop of ISC strength values in relation to the VBO is more severe in matrixdominated properties such as ILSS and IPSS, owing to the higher void content, void size and distribution found in the ISC laminates by means of micro-CT and matrix digestion testing. By contrast, the decrease of fibre-dominated properties is less severe but still existent. This was attributed in the same way to the detrimental effect of void content and distribution but other factors may have affected such as residual stresses and fibre waviness.

The results concluded that an overall mechanical response equivalent to autoclave levels can be achieved by OoA techniques such as VBO and hot-press. However, laser-assisted AFP with ISC is presented as a complex process that needs to be further optimized in order to achieve a comparable mechanical response. Higher mechanical values could be achieved by optimizing the manufacturing parameters such as temperature profile, lamination speed and compaction roller material and load. Better quality raw thermoplastic tapes, especially with constant ply thickness, fewer intralaminar voids and good fibre/matrix distribution, would be also beneficial for optimal lamination and final quality of the laminates, as also concluded by other investigations. ${ }^{33,34,54,57}$ The use of re-passes may also be of assistance for a better final laminate quality. Thus, further research focused on the investigation of different material grade and different lamination strategies for the improvement of the quality of ISC laminates is proposed.

\section{Acknowledgements}

The authors of this paper want to acknowledge Airbus Group and the government of the Community of Madrid for their financial support to the research and development projects.
Also, the authors would like to acknowledge Auckland Bioengineering Institute for the micro-CT facilities used in this study, and their technician Mr Dane Gerneke for his assistance with scanning and reconstruction.

\section{Declaration of conflicting interests}

The author(s) declared no potential conflicts of interest with respect to the research, authorship, and/or publication of this article.

\section{Funding}

The author(s) received no financial support for the research, authorship, and/or publication of this article.

\section{ORCID iDs}

Diego Saenz-Castillo (D) https://orcid.org/0000-0003-43781452

Alfredo Güemes (1) https://orcid.org/0000-0002-6700-3455

\section{References}

1. Rosselli F, Santare MH and Güçeri SI. Effects of processing on laser assisted thermoplastic tape consolidation. Compos Part A Appl Sci Manuf 1997; 28: 1023-1033.

2. Funck R and Neitzel M. Improved thermoplastic tape winding using laser or direct-flame heating. Compos Mamuf 1995; 6: 189-192.

3. Pistor CM, Yardimci MA and Güçeri SI. On-line consolidation of thermoplastic composites using laser scanning. Compos Part A Appl Sci Manuf 1999; 30: 1149-1157.

4. Pistor CM and Güçeri SI. Crystallization of on-line thermoplastic composites. J Compos Mater 1998; 33: 306-324.

5. Stokes-Griffin CM and Compston P. Optical characterisation and modelling for oblique near-infrared laser heating of carbon fibre reinforced thermoplastic composites. Opt Lasers Eng 2015; 72: 1-11.

6. Stokes-Griffin CM and Compston P. The effect of processing temperature and placement rate on the short beam strength of carbon fibre-PEEK manufactured using a laser tape placement process. Compos Part A Appl Sci Manuf 2015; 78: 274-283.

7. Grouve WJB, Warnet LL, Rietman B, et al. Optimization of the tape placement process parameters for carbon-PPS composites. Compos Part A Appl Sci Manuf 2013; 50: 44-53.

8. Comer AJ, Ray D, Obande WO, et al. Mechanical characterisation of carbon fibre-PEEK manufactured by laser-assisted automated-tape-placement and autoclave. Compos Part A Appl Sci Manuf 2015; 69: 10-20.

9. Rodriguez-Lence F, Martin MI, Horcajo KF. In-situ consolidation of integrated thermoplastic fuselage panels: the future in structural commercial aerocomposites. In: ECCM 18 - 18th European conference on composite materials, Athens, Greece, 2018.

10. Martín MI, Rodríguez-Lence F, Güemes A, et al. On the determination of thermal degradation effects and detection techniques for thermoplastic composites obtained by 
automatic lamination. Compos Part A Appl Sci Mantf 2018; 111: 23-32.

11. Hoang MD, Simpson JF, Hoa SV. Mechanical properties of thermoplastic composites made by automated fiber placement. In: ICCM20, Copenhagen, 2015.

12. Van Hoa $S$, Duc Hoang $M$ and Simpson J. Manufacturing procedure to make flat thermoplastic composite laminates by automated fibre placement and their mechanical properties. I Thermoplast Compos Mater 2017; 30: 1693-1712.

13. Rodriguez-Lence $F$, Lorenzo $E$, Zuazo $M$, et al. Activities on in-situ consolidation by automated placement techmologies. In: Proceedings of I6th the European conferences on composites materials (ECCM16), Seville, Spain, 2014.

14. Amir Khan M, Mitschang $P$ and Schledjewski R. Tracing the void content development and identification of its effecting parameters during in situ consolidation of thermoplastic tape material. Poly Polym Compos 2010; 18(1): $1-15$.

15. Chu Q, Li Y, Xiao J, et al. Processing and characterization of the themoplastic composites manufactured by ultrasonic vibration-assisted automated fiber placement. $J$ Thermoplast Compos Mater 2018; 31: 339-358.

16. Francesco MD, Giddings PF, Scott M, et al. Influence of laser power density on the meso-structure of thermoplastic composite preforms manufactured by automated fibre placement. In: SAMPE 2016, Long Beach, CA, 23-26 May 2016.

17. Saenz-Castillo D, Martín MI, Calvo S, et al. Effect of processing parameters and void content on mechanical properties and NDI of thermoplastic composites. Compos Part A App/Sci Manif 2019; 121: 308-320.

18. Schledjewski R. Thermoplastic tape placement process in situ consolidation is reachable. Plastics Rubber Compos 2009; 38(9-10): 379-386.

19. Schledjewski R. Thermoplastic tape placement - challenging the autoclave process. VDI Ber 245-25l.

20. Stokes-Griffin CM, Kollmannsberger A, Elhard S, et al. Manufacture of steel-CF/PA6 hybrids in a laser tape placement process: effect of first-ply placement rate on thermal history and lap shear strength. Compos Part $A$ Appl Sci Manuf 2018; 111: 42-53.

21. Khan MA, Mitschang $\mathbf{P}$ and Schledjewski R. Parametric study on processing parameters and resulting part quality through thermoplastic tape placement process. $J$ Compos Mater $2013 ; 47: 485-499$.

22. Zhang D, Heider D, Advani SG, et al. Out of autoclave consolidation of voids in continuous fiber reinforced thermoplastic composites. In: SAMPE, Long Beach, CA, 2013.

23. Biron M. Thermoplastics and thermoplastic composites. 2nd ed. New York: William Andrew, 2012, pp. 1-1044.

24. Thermoplastic aromatic polymer composites - lst ed., https://www.elsevier.com/books/thermoplastic-aromaticpolymer-composites/cogswell/978-0-7506-1086-5 (accessed 20 October 2018).

25. Vaidya UK and Chawla KK. Processing of fibre reinforced thermoplastic composites. Int Mater Rev 2008; 53: $185-218$.
26. Valverde MA, Kupfer R, Kawashita LF, et al. Effect of processing parameters on quality and strength in thermoplastic composite injection overmoulded components. In: ECCM18 - 18th European conference on composite materials, Athens, Greece, 2018, p. 8.

27. Costa AP, da Botelho EC, Costa ML, et al. A review of welding technologies for thermoplastic composites in aerospace applications. J Aerosp Technol Manag 2012; 4: 255-266.

28. Tiemey $\mathbf{J}$ and Gillespie JW. Modeling of heat transfer and void dynamics for the thermoplastic composite tow-placement process. J Compos Mater 2003; 37: 1745-1768.

29. Oromiehie E. In-sint process monitoring in attomated fibre placement-based manufacturing of advanced composites. Sydney, Australia: UNSW (University of New South Wales), 2017.

30. Khan MA, Mitschang $\mathbf{P}$ and Schledjewski $\mathbf{R}$. Identification of some optimal parameters to achieve higher laminate quality through tape placement process. Adv Polym Technol 2010; 29: 98-111.

31. Gao S-L and Kim J-K. Cooling rate influences in carbon fibre/PEEK composites. Part 1. Crystallinity and interface adhesion. Compos Part A Appl Sci Manuf 2000; 31 : $517-530$.

32. Schledjewski $\mathbf{R}$ and Miaris A. Thermoplastic tape placement by means of diode laser heating. In: International SAMPE symposium and exhibition (proceedings), Baltimore, MD, USA, 2009.

33. Gruber MB, Lockwood IZ, Dolan TL, et al. Thermoplastic in-situ placement requires better impregnated tapes and tows. In: Proceedings of the 2012 SAMPE conference and exhibition, Baltimore, MD, 2012.

34. Lamontia MA, Gruber MB, Systems A, et al. Remaining developments required for commercializing in situ thermoplastic ATP. In: $S A M P E$, Baltimore, MD, USA, 2007 , p. 15.

35. Hassan $\mathrm{MH}$, Othman AR and Kamaruddin S. Void content determination of fiber reinforced polymers by acid digestion method. Adv Mater Res 2013; 795: 64-68.

36. Dean S, McDonough W, Dunkers J, et al. A test method to deteminine the fiber and void contents of carbon/glass hybrid composites. J ASTM Int 2004; 1: 12076

37. Little JE, Yuan $X$ and Jones MI. Characterisation of voids in fibre reinforced composite materials. NDTE Int 2012; 46: 122-127.

38. Hernández S, Sket F, González C, et al. Optimization of curing cycle in carbon fiber-reinforced laminates: void distribution and mechanical properties. Compos $S c i$ Technol 2013; 85: 73-82.

39. Tretiak I and Smith RA. A parametric study of segmentation thresholds for X-ray CT porosity characterisation in composite materials. Compos Part A App/ Sci Mamuf $2019 ; 123$ : 10-24.

40. Ramesh A, Battley $M$, Allen $T$, et al. Characterising voids and wrinkles in curved carbon fibre reinforced polymer parts using $\mu-C T$ and optical microscopy. In: 18 th European conferences of composite materials. ECCM18, Athens, Greece, 2018. 
41. APC-2 PEEK thermoplastic polymer Technical Data Sheet, https://www.cytec.com/sites/default/files/datash eets/APC-2 PEEK 031912-01.pdf.

42. Cytec. Technical data sheet. APC-2-PEEK thermoplastic polymer.

43. Solvay Group. Technical data sheet. APC-2 PEEK thermoplastic polymer prepreg.

44. Martín MI. Modelización del proceso de laminación automática y consolidación in-situ con materiales compuestos termoplasticos APC2/AS4. Thesis Manuscript, ETSIAE, Universidad Politécnica de Madrid, 2019.

45. ISO 11357-3:2018(E). Plastics - differential scanning calorimetry (DSC), part 3: determination of temperature and enthalpy of melting and crystallization.

46. Blundell DJ. On the interpretation of multiple melting peaks in poly(ether ether ketone). Polymer 1987; 28: 2248-2251.

47. Schindelin J, Rueden CT, Hiner MC, et al. The ImageJ ecosystem: an open platform for biomedical image analysis. Mol Reprod Dev 2015; 82: 518-529.

48. Birt EA and Smith RA. A review of NDE methods for porosity measurement in fibre-reinforced polymer composites. Insight 2004; 46: 681-686.

49. Ghiorse SR. Effect of void content on the mechanical properties of carbon epoxy laminates. SAMPE $Q$ 1993; 24: 54-59.
50. Landro LD, Montalto A, Bettini P, et al. Detection of voids in carbon/epoxy laminates and their influence on mechanical properties. Polym Compos 2017; 25: 10.

51. Liu L, Zhang B-M, Wang D-F, et al. Effects of cure cycles on void content and mechanical properties of composite laminates. Compos Struct 2006; 73; 303-309.

52. Sloan J. OOA: thermoplastic alternative targets performance spec. CompositesWorld, 18 February 2016.

53. Davis T, Healy D, Bubeck A, et al. Stress concentrations around voids in three dimensions: the roots of failure. $J$ Struct Geol 2017; 102: 193-207.

54. Lamontia MA, Gruber MB, Drive S, et al. In situ thermoplastic ATP needs flat tapes and tows with few voids. In: SEICO O9-Paris, France, 2009.

55. Wisnom MR, Reynolds $T$ and Gwilliam N. Reduction in interlaminar shear strength by discrete and distributed voids. Compos Sci Technol 1996; 56: 93-101.

56. Fujihara K, Huang Z-M, Ramakrishna S, et al. Influence of processing conditions on bending property of continuous carbon fiber reinforced PEEK composites. Compos Sci Technol 2004; 64: 2525-2534.

57. Rodríguez-Lence F, Zuazo M, Calvo S. In-situ consolidation of PEEK composites by automated placement technologies. In: 20th international conference on composite materials, Copenhagen, 2015, p. 9. 